\title{
Dinâmica da celularidade do colostro de vacas da raça Holandesa no pós-parto imediato
}

\author{
[Cell dynamics of Holstein cow colostrum immediately after parturition] \\ V. Gomes, K.M. Madureira, A.M.M.P. Della Libera, M.G. Blagitz, M. Alves, \\ F. Baptistella, F.J. Benesi
}

Faculdade de Medicina Veterinária e Zootecnia - FMVZ - Universidade de São Paulo - USP

Avenida Orlando Marques de Paiva, 87 - Cidade Universitária

05508-270 - São Paulo, SP

\begin{abstract}
RESUMO
Avaliou-se a celularidade do colostro de 53 vacas da raça Holandesa, utilizando-se 171 amostras, colhidas após a primeira e a segunda ordenha pós-parto. Para a análise citológica quantitativa e qualitativa, foram utilizadas as técnicas de microscopia direta e citocentrifugação. O total de leucócitos obtido por contagem microscópica direta foi de $0,878 \times 10^{6}$ e $1,260 \times 10^{6}$, antes da primeira e da segunda ordenha, respectivamente, e os valores da mediana dos fagócitos obtidos antes da primeira e da segunda ordenha

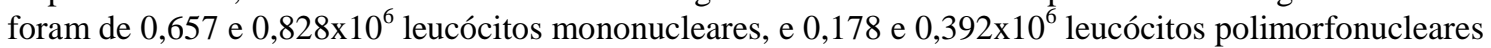
$(\mathrm{P}<0,0001)$. Os valores da mediana dos tipos leucocitários, antes da primeira e da segunda ordenha, foram: $0,640 \times 10^{6}$ e 0,772 monócitos/células epiteliais; $0,136 \times 10^{6}$ e 0,098 linfócitos; $0,045 \times 10^{6}$ e $0,203 \times 10^{6}$ neutrófilos, respectivamente. Concluiu-se que o colostro bovino da segunda ordenha apresentou aumento da quantidade de células somáticas e leucócitos polimorfonucleares/mL de colostro. Essas variações podem estar relacionadas à importância do colostro aos neonatos, ou a modificações fisiológicas e de defesa da glândula mamária, durante o período de adaptação dela.
\end{abstract}

Palavras-chave: bovino de leite, colostro, citologia, fagócitos

\begin{abstract}
Colostrum cellularity was studied in 53 Holstein cows using 171 samples, collected before the first and second postpartum milking. Direct microscopic counts and cytocentrifugation were used in the quantitative and qualitative cytological analyses. The total number of leukocytes obtained by means of direct microscopic count was equal to $0.878 \times 10^{6}$ and $1,260 \times 10^{6}$, before the first and second milking, respectively. The median of phagocyte counts before the first and second milking were, respectively,0.657 and $0.828 \times 10^{6}$ mononuclear leukocytes, and 0.178 and $0.392 \times 10^{6}$ polymorphonuclear leukocytes $(P<0.0001)$. The median of leukocyte counts, before the first and second milking were, respectively, 0.640 $\times 10^{6}$ and 0.772 monocytes/epithelial cells; $0.136 \times 10^{6}$ and 0.098 lymphocytes; $0.045 \times 10^{6}$ and $0.203 \times$ $10^{6}$ neutrophils. It was concluded that bovine colostrum of the second milking showed an increase in the number of somatic cells and polymorphonuclear leukocytes and polymorphonuclear leukocytes $/ \mathrm{mL}$. This variation may be either related to the importance of colostrum to neonates, or to physiological and defense changes that occur in the mammary gland during immediate after postpartum.
\end{abstract}

Keywords: dairy cow, colostrum, cytology, phagocytes

\section{INTRODUÇÃO}

As células do colostro bovino são importantes para a defesa da glândula mamária (Paape et al., 2003) e para a resposta imunológica sistêmica de bezerros neonatos, após a ingestão desse alimento (Barrington e Parish, 2001; Tizard, 2002). Além disso, alterações no número dessas células podem indicar uma condição fisiológica (Schalm e Lasmanis, 1968) ou inflamatória da

Recebido em 9 de fevereiro de 2010

Aceito em 14 de abril de 2011

E-mail:viviani.gomes@ufpr.br 
glândula mamária (Schalm et al., 1971). No início e no final da lactação, ocorre aumento da celularidade do leite devido à maior liberação celular associada à menor produção de leite (Schalm et al., 1971; Schultz, 1977; Dahoo e Meek, 1982).

McDonald e Anderson (1981), ao estudarem a contagem de células somáticas na secreção láctea de três vacas da raça Holandesa durante o período seco, encontraram valor médio de células correspondente a $2,5 \times 10^{6}$ células somáticas/mL de colostro, no $25^{\circ}$ dia antes do parto, que diminuiu até atingir o valor médio de 0,6×106 células somáticas/mL, logo após o parto. Jensen e Eberhart (1981) estudaram a secreção láctea proveniente de 52 quartos mamários, durante o início do período seco até o período pós-parto. Estes autores encontraram média geométrica de $0,36 \times 10^{6}$ células somáticas $/ \mathrm{mL}$ no último dia de lactação das vacas; $18,0 \times 10^{6}$ células somáticas $/ \mathrm{mL}$ após sete dias do início da secagem, que diminuiu para $0,28 \times 10^{6}$ células somáticas/mL, seis dias do parto após o parto.

Poucos autores analisaram a contagem diferencial de leucócitos da secreção láctea de vacas pela técnica de citocentrifugação. Lee et al. (1980), Jensen e Eberhart (1981) e Östensson (1993) justificaram a importância do exame diferencial das células do leite de bovinos na interpretação da condição inflamatória, pois a presença ou o predomínio de uma determinada célula representaria a necessidade específica da função celular por ela exercida. No colostro essa importância é aumentada pela crescente manifestação de mamite no período colostral e início da lactação (Mc Donald e Anderson, 1981). Östensson (1993) determinou as possíveis variações que pudessem ocorrer durante a lactação, nas diferentes fases dessa ou entre as ordenhas.

Em bovinos, todos os tipos de células envolvidas na resposta imune estão presentes na glândula mamária nos diferentes estádios de gestação. No início da gestação, tem-se um aumento nos números de células epiteliais, linfócitos $\mathrm{T}$ e macrófagos; logo após, observa-se aumento nos números de linfócitos $\mathrm{B}$ secretores de imunoglobulinas de classe $A$, porém pouco se sabe sobre a atividade funcional dessas células (Salmon, 1999).
Classicamente, Schalm et al. (1971) descreveram na secreção láctea de vacas a presença de dois grupos de células epiteliais (vacuolizadas e não vacuolizadas), neutrófilos, eosinófilos, linfócitos, monócitos, grande célula escamosa, além da presença de debris de células epiteliais, núcleos livres e corpúsculos de colostro, também denominados de corpúsculos de Niessen; esses últimos, apenas na fase colostral da secreção láctea. Tais autores, ao copilarem a literatura da época, consideraram as células epiteliais como predominantes no leite normal. As células nucleadas mais abundantes no colostro de vacas hígidas são macrófagos, que atuam na fagocitose de bactérias e fungos e interagem com linfócitos através de citocinas produzidas por eles (Smith e Goldman, 1968).

McDonald e Anderson (1981) afirmaram que, na secreção láctea de vacas Holandesas, nos últimos 25 dias do período seco, há predomínio de macrófagos e linfócitos. Cinco dias antes do parto, observaram diminuição na quantidade de linfócitos e, logo após o parto, verificaram que todas as células da secreção eram macrófagos, e que os neutrófilos polimorfonucleares estavam em pequeno número ou ausentes em todas as secreções avaliadas. A quantidade de linfócitos observada foi inferior a $0,05 \times 10^{6}$ linfócitos $/ \mathrm{mL}$ de colostro durante os oito primeiros dias de lactação. A quantidade excessiva de macrófagos presentes no colostro foi justificada pela migração dessas células através do tecido conectivo da glândula mamária para a secreção láctea. Além disso, afirmaram que a pequena quantidade de neutrófilos na secreção láctea durante o período seco e início da lactação poderia ser a justificativa para a susceptibilidade da glândula mamária durante esse período.

Jensen e Eberhart (1981) verificaram predomínio de macrófagos na secreção láctea durante o período seco e início da lactação. Inicialmente encontraram maior proporção de neutrófilos no início do período seco, que diminuiu com o avançar do período de secagem e início da lactação subsequente. No entanto, a quantidade de linfócitos aumentou durante o período de secagem e início da próxima lactação. Verificaram, ainda, maior número de leucócitos, pelo aumento na quantidade de neutrófilos, macrófagos e linfócitos na secreção láctea de vacas com infecção intramamária. 
Dulin et al. (1982) observaram predomínio de polimorfonucleares neutrófilos no leite de vacas, seguido de macrófagos, linfócitos e monócitos. Miller et al. (1991) avaliaram a secreção colostral de vacas primíparas e observaram valores médios relativos de 39,4; 16,5; 33,0; e $10,8 \%$, respectivamente, de neutrófilos, linfócitos, macrófagos e células epiteliais, na segunda semana pós-parto.

Devido à importância das células do colostro bovino para a defesa da glândula mamária e à resposta imunológica sistêmica de bezerros neonatos, o objetivo da presente pesquisa foi avaliar a contagem total e diferencial das células do colostro de vacas da raça Holandesa, assim como verificar a influência do número de ordenha pós-parto na secreção láctea desses animais.

\section{MATERIAL E MÉTODOS}

Foram estudados dois grupos de fêmeas bovinas da raça Holandesa pertencentes a quatro propriedades leiteiras localizadas no estado de São Paulo. As vacas foram transferidas e colocadas em piquete maternidade entre o $245^{\circ} \mathrm{e}$ $250^{\circ}$ dias de gestação. Imediatamente após o parto, foram separadas dos neonatos e encaminhadas para a sala de ordenha, onde foi realizada a colheita das amostras. Os neonatos não foram amamentados pelas mães.

Os animais foram distribuídos em dois grupos experimentais. O primeiro grupo foi constituído de vacas com menos de seis horas pós-parto, e o segundo por vacas entre seis e 12 horas pósparto. Após a comunicação do parto, realizavamse as colheitas, de acordo com o horário em que a equipe chegava à propriedade. As amostras foram catalogadas segundo os grupos descritos. Dessa forma, obtiveram-se 212 amostras de colostro, provenientes de 53 vacas. Como as amostras positivas ao exame microbiológico foram descartadas, restaram 171 amostras de leite, provenientes das 53 vacas.

Para colher as amostras de colostro, procediamse à limpeza e à desinfecção dos tetos, com uso de água e hipoclorito, secagem com papel toalha individual e desinfecção dos orifícios dos tetos com etanol a 70\%. A primeira alíquota de colostro foi colhida em tubos Falcon estéreis com capacidade de $50 \mathrm{~mL}$, no qual foram adicionados 20mL de colostro puro, para a realização das análises citológicas. A segunda foi colhida em tubos de vidro estéreis com capacidade de $5 \mathrm{~mL}$ para a realização do exame bacteriológico.

As amostras transportadas sob refrigeração ao laboratório, a aproximadamente $4^{\circ} \mathrm{C}$, foram acondicionadas em caixa de material isotérmico, imersas em gelo triturado. No laboratório, a primeira alíquota foi dividida e disposta em dois frascos, dentro da capela de esterilização, em condições de assepsia: $1 \mathrm{~mL}$ de colostro em frasco de vidro com capacidade de $5 \mathrm{~mL}$, acrescido de $1 \mathrm{~mL}$ de solução de tampão fosfato (PBS), utilizados na análise citológica quantitativa da secreção láctea; e $1 \mathrm{~mL}$ de colostro em tubos Falcon com capacidade de 50mL, acrescido de $49 \mathrm{~mL}$ de PBS, para análise citológica qualitativa.

O colostro foi diluído na proporção de 1:1 em PBS em tubos de vidro com capacidade de $5 \mathrm{~mL}$ e, posteriormente, distribuído em uma área de $1 \mathrm{~cm}^{2}$, em lâmina de vidro para microscopia, previamente limpa e desengordurada. Após 24 horas de secagem em temperatura ambiente, a lâmina foi imersa em metanol por 15 minutos para fixação e, a seguir, corada pela técnica de Rosenfeld (Della Libera et al., 2004). Para a avaliação do número de células, foram contados 100 campos microscópicos, utilizando-se microscópio óptico comum com objetiva de imersão com aumento de $1000 \mathrm{X}$. O resultado da contagem de cada amostra foi multiplicado pelo fator do microscópio e por dois em função da diluição inicial da amostra, obtendo-se o valor do número de células/mL de colostro. Durante a contagem, os fagócitos foram diferenciados em mononucleares e polimorfonucleares.

Para a análise citológica qualitativa do colostro, foi realizada contagem diferencial pela técnica da citocentrifugação (Della Libera et al., 2004). Foi adicionado $1 \mathrm{~mL}$ de colostro em um frasco Falcon contendo $49 \mathrm{~mL}$ de PBS. As células foram separadas por centrifugação com força centrífuga relativa (FCR) igual a 1500rpm, durante 10 minutos sob refrigeração a $4^{\circ} \mathrm{C}$. A centrifugação permitiu a separação do colostro em três fases nítidas: o "botão" celular, uma porção fluida intermediária (sobrenadante) e uma camada de gordura. A camada de gordura e o sobrenadante foram desprezados. Dessa forma, 
restou apenas o botão de células decantado no fundo do frasco. Subsequentemente, esse botão foi desprendido do frasco por aspersão, por meio da aplicação de fracos jatos de PBS, sendo, então, homogeneizado, completando-se o volume com PBS refrigerado (refazendo o volume primitivo de $50 \mathrm{~mL}$ ). A suspensão foi novamente centrifugada, nas condições já mencionadas, com o sobrenadante desprezado e o botão de células ressuspendido em $1 \mathrm{~mL}$ de meio enriquecido RPMI 1640, para melhorar as condições de preservação.

Alíquotas de $200 \mu \mathrm{L}$ da suspensão celular do colostro, preparadas como descrito anteriormente, foram submetidas à citocentrifugação a uma força centrífuga relativa (FCR) de 20G durante seis minutos. Os esfregaços de colostro foram corados pelo método de Rosenfeld (1947) e examinados em microscopia de campo claro, com aumento de 1000X. Observaram-se os tipos celulares predominantes, linfócitos, monócitos, neutrófilos, eosinófilos e basófilos, e realizou-se a contagem diferencial das células do colostro bovino. Os resultados para os diferentes tipos celulares foram expressos em valores relativos (\%).

Os resultados obtidos segundo as variáveis estudadas foram submetidos ao teste de normalidade de Kolmogorov-Smirnov. Os valores da contagem total de leucócitos e os valores absolutos dos tipos leucocitários apresentaram distribuição não paramétrica, sendo calculadas as medianas de cada parâmetro avaliado, e a significância das diferenças obtida por meio do teste de Kruskal-Wallis (Sampaio,
1998). Os valores relativos (\%) da contagem diferencial de leucócitos apresentaram distribuição paramétrica, foram submetidos à análise de variância, e a significância das diferenças obtida por meio do teste de Fisher (Sampaio, 1998). As análises estatísticas foram processadas com o auxílio do programa estatístico computadorizado (Minitab, 2000).

\section{RESULTADOS E DISCUSSÃO}

Das 212 amostras de colostro colhidas, 41 $(19,3 \%)$ foram positivas ao exame bacteriológico, e 171 (80,7\%) negativas. As amostras positivas ao exame bacteriológico foram excluídas da presente pesquisa, conforme critério descrito no Material e Métodos.

Foram encontradas alterações precoces na celularidade do colostro de vacas hígidas da raça Holandesa, quando se compararam a primeira e a segunda ordenha, pois o intervalo de tempo entre as ordenhas não ultrapassou seis horas, e todas as amostras foram colhidas antes das primeiras 12 horas pós-parto.

A mediana do total de leucócitos do colostro, obtida por contagem pela técnica de microscopia direta, antes da primeira e da segunda ordenha, está na Tab. 1. Estes valores foram mais elevados que os observados por Mc Donald e Anderson (1981), Jensen e Eberhart (1981). Provavelmente essas divergências são decorrentes dos diferentes manejos sanitários praticados nos rebanhos estudados, ou do momento da colheita das amostras pós-parto.

Tabela 1. Mediana dos valores absolutos dos leucócitos (x10 $0^{6}$ células/mL), conforme o momento da ordenha pós-parto

\begin{tabular}{cccc}
\hline Ordenha & $\begin{array}{c}\text { Mononucleares } \\
\left(\times 10^{6}\right)\end{array}$ & $\begin{array}{c}\text { Polimorfonucleares } \\
\left(\times 10^{6}\right)\end{array}$ & $\begin{array}{c}\text { Leucócitos totais } \\
(\mathrm{x} \mathrm{10})\end{array}$ \\
\hline Primeira & $0,657 \mathrm{~A}$ & $0,178 \mathrm{~B}$ & $0,878 \mathrm{~B}$ \\
Segunda & $0,828 \mathrm{~A}$ & $0,392 \mathrm{~A}$ & $1,260^{\mathrm{a}}$ \\
\hline Significância & $\mathrm{P}>0,09$ & $\mathrm{P}<0,0001$ & $\mathrm{P}<0,002$ \\
\hline
\end{tabular}

Valores seguidos por letras distintas na mesma coluna indicam diferenças estatísticas entre eles (Kruskal-Wallis).

Os valores da mediana dos fagócitos obtidos antes da primeira e da segunda ordenha estão na Tab. 1. Observou-se diferença na contagem de células polimorfonucleares (PMN), isto é, contagem mais alta na segunda ordenha; o mesmo fato foi observado na contagem total de leucócitos ( $\mathrm{P}<0,0001$ e $\mathrm{P}<0,002$, respectivamente), em decorrência do aumento de PMN. Na contagem de células mononucleares (MN) não ocorreu diferença entre as ordenhas $(\mathrm{P}>0,09)$. 
Este aspecto aparentemente fisiológico, aponta para objetivos diferenciados, considerando-se os dois momentos analisados, pois os fatores imunológicos do colostro antes da primeira ordenha visam particularmente à imunidade neonatal e, em seguida, à imunidade da glândula mamária materna (Paape et al., 2003). Acreditase que o quadro diferencial dos leucócitos do colostro reflete a necessidade específica da função celular exercida pelos leucócitos predominantes (Östensson, 1993).

Utilizando-se a contagem diferencial dos leucócitos do colostro em lâminas obtidas por citocentrifugação, foi possível estabelecer a proporção dos diferentes tipos de leucócitos, que pode estar alterada de acordo com estímulos fisiológicos, como a fase da lactação. Na literatura consultada, poucos trabalhos estudaram a citologia do colostro bovino. Todos os tipos de leucócitos foram observados no colostro bovino, com exceção dos basófilos. Por meio da análise microscópica dos esfregaços lácteos obtidos por citocentrifugação, também foram encontrados debris celulares e corpúsculos de colostro, denominados por Schalm et al. (1971) como corpúsculos de Niessen.
Quanto aos valores relativos dos diferentes tipos de leucócitos do colostro (Tab. 2), não foram observadas diferenças significativas entre ordenhas, e quanto aos valores absolutos, observou-se diferença significativa entre as ordenhas apenas quanto aos neutrófilos (Tab. 3), isto é, maiores nos obtidos antes da segunda ordenha.

No presente estudo, optou-se por não classificar separadamente as células epiteliais e os macrófagos, pois muitas vezes foi impossível diferenciá-las por sua semelhança morfológica. Além disso, a literatura ainda é controversa sobre o assunto, pois alguns autores consideram que os macrófagos podem sofrer variações morfológicas de acordo com seus diferentes graus de ativação e podem ser classificados como células epiteliais (Schalm et al. 1971; Lee et al., 1980; Jensen e Eberhart, 1981). Inclusive foi detectado que células anteriormente consideradas como epiteliais e com capacidade de fagocitar (Schalm et al., 1971) eram, na realidade, células da série monócito/macrófago (Lee et al., 1980; Jensen e Eberhart, 1981).

Tabela 2. Valores relativos (\%) de leucócitos do colostro bovino, conforme o momento da ordenha pósparto

\begin{tabular}{lcccc} 
Ordenha & Neutrófilos & Linfócitos & $\begin{array}{c}\text { Monócitos + células } \\
\text { epiteliais }\end{array}$ & Eosinófilos \\
\hline Primeira & $13,3 \pm 19,4$ & $16,4 \pm 9,8$ & $69,5 \pm 17,4$ & $0,27^{\mathrm{a}}$ \\
Segunda & $18,5 \pm 21,4$ & $13,4 \pm 11,8$ & $68,0 \pm 21,0$ & $0 \mathrm{~A}$ \\
\hline Significância & $\mathrm{P}>0,2$ & $\mathrm{P}>0,17$ & $\mathrm{P}>0,7$ & $\mathrm{P}>0,3$ \\
\hline
\end{tabular}

Não se observou diferença estatística entre os valores da primeira e da segunda ordenha (Teste de Fisher).

Tabela 3. Valores medianos absolutos de neutrófilos, linfócitos e macrófagos/células epiteliais do colostro bovino, conforme a ordem de ordenha pós-parto

\begin{tabular}{lccc}
\hline Ordenha & $\begin{array}{c}\text { Neutrófilos } \\
\left(\times 10^{6}\right)\end{array}$ & $\begin{array}{c}\text { Linfócitos } \\
(\mathrm{x} \mathrm{110})\end{array}$ & $\begin{array}{c}\text { Monócitos + células } \\
\left.\text { epiteliais }(\mathrm{x} \mathrm{10})^{6}\right)\end{array}$ \\
\hline Primeira & $0,045 \mathrm{~B}$ & $0,136 \mathrm{~A}$ & $0,640^{\mathrm{a}}$ \\
Segunda & $0,203 \mathrm{~A}$ & $0,098 \mathrm{~A}$ & $0,772^{\mathrm{a}}$ \\
\hline Significância & $\mathrm{P}<0,0001$ & $\mathrm{P}>0,7$ & $\mathrm{P}>0,2$ \\
\hline
\end{tabular}

Valores seguidos por letras distintas na mesma coluna indicam diferença entre eles.

A população celular observada com a avaliação pela técnica microscópica direta, técnica convencional, foi composta, predominantemente, por leucócitos mononucleares, fato também verificado com $\mathrm{o}$ uso do método da citocentrifugação, considerado padrão para a diferenciação dos tipos de leucócitos presentes no leite, uma vez que a técnica convencional permite diferenciação mais limitada.

Dulin et al. (1982) avaliaram a citologia do leite bovino usando o método de citocentrifugação e obtiveram predomínio de neutrófilos, seguidos em números decrescentes pelos macrófagos, linfócitos e eosinófilos. Os resultados do 
presente estudo são divergentes em razão da influência do período de lactação e da sanidade da glândula mamária.

Miller et al. (1991) encontraram valores relativos de neutrófilos e menores de macrófagos e células epiteliais, e proporção semelhante de linfócitos no colostro de vacas na segunda semana pósparto. Os resultados da presente pesquisa, provavelmente pelos diferentes momentos de ordenha, divergem dos obtidos pelos autores citados.

O número total de células do colostro e o valor relativo de linfócitos citados por Tizard (2002) são menores que os observados na presente investigação. Deve-se, ainda, ressaltar que uma das limitações encontradas pelo uso da técnica de citocentrifugação foi a dificuldade encontrada na diferenciação morfológica entre núcleos destacados do citoplasma de algumas células, principalmente de células epiteliais, e linfócitos, fato também destacado por Schalm et al. (1971). $\mathrm{Na}$ presente investigação, foram tomados cuidados para diferenciá-los (núcleos e linfócitos), sendo considerados o tamanho e a disposição da cromatina nuclear, pois os linfócitos possuem cromatina mais condensada que os outros leucócitos. Esse critério de diferenciação pode não ter sido utilizado em outras pesquisas, fato que pode ter aumentando, aparentemente, o número de linfócitos do colostro. Barrington e Parish (2001) também encontraram valores linfocitários mais altos que os observados nesta investigação.

\section{CONCLUSÕES}

Mesmo em mamas hígidas, após a primordial disponibilidade de mononucleares, há mobilização mais intensa de neutrófilos para o colostro, demonstrando variações celulares imediatas ao parto. Essas variações podem estar relacionadas à importância do colostro de primeira ordenha aos bezerros neonatos, ou podem representar modificações fisiológicas e de defesa da glândula mamária, durante o período de colostrogênese à lactogênese.

\section{REFERÊNCIAS BIBLIOGRÁFICAS}

BARRINGTON, G.M.; PARRISH, S.M. Bovine neonatal immnunology. Vet. Clin. N. Am.: Food Anim. Pract., v.17, p.463-477, 2001.

DAHOO, I.R.; MEEK, A.H. Somatic cells count in bovine milk. Can. Vet. J., v.23, p.119-125, 1982.

DELLA LIBERA, A.M.M.P.; ARAÚJO, W.P.; SATIKO, S.S. et al. Citologia do leite de búfalas (Bubalus bubalis) hígidas, criadas no estado de São Paulo, Brasil. Cienc. Rural, v.34, p.10871092, 2004.

DULIN, A.M.; PAAPE, M.J.; WEINLAND, B.T.. Cytospin centrifuge in differencial counts of milk somatic cells. J. Dairy Sci., v.65, p.12471251, 1982.

JENSEN, D.L.; EBERHART, R.J. Total e differential cell count in secretions of the nonlactating bovine mammary gland. Am. J. Vet. Res., v.42, p.743-747, 1981.

LEE, C.; WOODING, F.B.; KEMP, P. Identification, properties, and differential counts of cell populations using microscopy of dry cows secretions, colostrum and milk from normal cows. J. Dairy Res., v.47, p.39-50, 1980.

McDONALD, J.S.; ANDERSON, A.J. Total and diferential somatic cell counts in secretions from noninfected bovine mammary glands: the peripartum period. Am. J. Vet. Res., v.45, p.1.366-1.368, 1981.

MILLER, R.H.; PAAPE, M.J.; FULTON, L.A. Variations in milk somatic cells of heifers at first calving. J. Dairy Sci., v.74, p.3782-3790, 1991.

MINITAB - statistical software adapted for education 13.0 release: The student edition. User's manual. New York: Addison - Wesley, 2000.

ÖSTENSSON, K. Trafficing of leukocytes and immunoglobulin isotypes in the bovine udder: studies of milk, lymph and blood from cows with healthy and mastitic mammary glands. 1993. 67f. Tese (Doctor) - University of Agricultural Sciences, Faculty of Veterinary Medicine, Uppsala, Swedish. 
PAAPE, M.J.; BANNERMAN, D.D.; ZHAO, X. et al. The bovine neutrophil: structure and function in blood and milk. Vet. Res., v.34, p.597-627, 2003.

ROSENFELD, G. Corante pancrômico para hematologia e citologia clínica: nova combinação dos componentes de May-Grunwald e do Giemsa num só corante de emprego rápido. Mem. Inst. Butantan, v.20, p.329-335, 1947.

SALMON, H. The mammary gland and neonate mucosal immunity. Vet. Immunol. Immunopathol., v.72, p.143-155, 1999.

SAMPAIO, I.B. Estatística aplicada à experimentação animal. Belo Horizonte: Universidade Federal de Minas Gerais, 1998. $221 \mathrm{p}$.
SCHALM, O.W.; LASMANIS, J. The leukocytes: origin and function in mastitis $J$. Am. Vet. Med. Assoc., v.153, p.1688-1694, 1968.

SCHALM, O.W.; CARROL, E.J.; JAIN, N.C. Bovine mastitis. Philadelphia: Lea e Febiger, 1971. 360p.

SCHULTZ, L.H. Somatic cell counting of milk in production testing programs as a mastitis control technique. J. Am. Vet. Med. Assoc., v.170, p.1244-1246, 1977.

SMITH, C.W.; GOLDMAN, A.S. The cells of human colostrums: in vitro studies of morphology and functions. Pediatr. Res., v.2, p.103, 1968.

TIZARD, I. R. Imunologia veterinária: uma introdução. 6. ed. São Paulo: Roca, 2002. 532 p. 